\title{
Systematic Review and Meta-Analysis of Community- and Choice-Based Health State Utility Values for Lung Cancer
}

\author{
Erik F. Blom ${ }^{1}$ (D) $\cdot$ Kevin ten Haaf ${ }^{1} \cdot$ Harry J. de Koning ${ }^{1}$
}

Published online: 5 August 2020

(c) The Author(s) 2020

\begin{abstract}
Background Using appropriate health state utility values (HSUVs) is critical for economic evaluation of new lung cancer interventions, such as low-dose computed tomography screening and immunotherapy. Therefore, we provide a systematic review and meta-analysis of community- and choice-based HSUVs for lung cancer.

Methods On 6 March 2017, we conducted a systematic search of the following databases: Embase, Ovid MEDLINE, Web of Science, Cochrane CENTRAL, Google Scholar, and the School of Health and Related Research Health Utility Database. The search was updated on 17 April 2019. Studies reporting mean or median lung cancer-specific HSUVs including a measure of variance were included and assessed for relevance and validity. Studies with high relevance (i.e. community- and choicebased) were further analysed. Mean HSUVs were pooled using random-effects models for all stages, stages I-II, and stages III-IV. For studies with a control group, we calculated the disutility due to lung cancer. A sensitivity analysis included only the methodologically most comparable studies (i.e. using the EQ-5D instrument and matching tariff). Subgroup analyses were conducted by time to death, histology, sex, age, treatment modality, treatment line, and progression status.

Results We identified and analysed 27 studies of high relevance. The pooled HSUV was 0.68 (95\% confidence interval [CI] $0.61-0.75)$ for all stages, 0.78 (95\% CI 0.70-0.86) for stages I-II, and 0.69 (95\% CI 0.65-0.73) for stages III-IV ( $p=0.02$ vs. stage I-II). Heterogeneity was present in each pooled analysis $\left(p<0.01 ; I^{2}=92-99 \%\right)$. Disutility due to lung cancer ranged from 0.11 (95\% CI 0.05-0.17) to 0.27 (95\% CI 0.18-0.36). In the sensitivity analysis with the methodologically most comparable studies, stage-specific HSUVs varied by country. Such studies were only identified for Canada, China, Spain, the UK, the USA, Denmark, Germany, and Thailand. In the subgroup analysis by time to death, HSUVs for metastatic non-small-cell lung cancer ranged from 0.83 (95\% CI 0.82-0.85) at $\geq 360$ days from death to 0.56 (95\% CI 0.46-0.66) at $<30$ days from death. Among patients with metastatic non-small-cell lung cancer, HSUVs were lower for those receiving third- or fourth-line treatment and for those with progressed disease. Results of subgroup analyses by histology, sex, age, and treatment modality were ambiguous.

Conclusions The presented evidence supports the use of stage- and country-specific HSUVs. However, such HSUVs are unavailable for most countries. Therefore, our pooled HSUVs may provide the best available stage-specific HSUVs for most countries. For metastatic non-small-cell lung cancer, adjusting for the decreased HSUVs in the last year of life may be considered, as may further stratification of HSUVs by treatment line or progression status. If required, HSUVs for other health states may be identified using our comprehensive breakdown of study characteristics.
\end{abstract}

Electronic supplementary material The online version of this article (https://doi.org/10.1007/s40273-020-00947-x) contains supplementary material, which is available to authorized users.

Erik F. Blom

e.f.blom@erasmusmc.nl

1 Department of Public Health, Erasmus MC, University

Medical Center Rotterdam, Internal Postal Address Na-2401,

P.O. Box 2040, 3000 CA Rotterdam, the Netherlands 


\section{Key Points for Decision Makers}

This systematic review and meta-analysis provides community- and choice-based health state utility values (HSUVs) for lung cancer, thereby enhancing the validity and reliability of future economic evaluations.

We show that HSUVs for lung cancer vary by stage and-among the methodologically most comparable studies-by country. Subgroup analyses indicated that, among those with metastatic non-small-cell lung cancer, HSUVs decreased throughout the last year of life and may be lower while undergoing a third or fourth treatment line or when disease progresses.

The presented evidence supports the use of stage-specific and-if available-country-specific HSUVs for lung cancer. In addition, for metastatic non-small-cell lung cancer, adjusting for the lower HSUV in the last year of life may be considered, as may further stratification by treatment line or progression status. If the use of HSUVs for other health states is required, our comprehensive breakdown of study characteristics may help identify suitable studies.

\section{Introduction}

Lung cancer is the leading cause of cancer-related mortality worldwide [1]. New interventions, such as low-dose computed tomography screening [2] and immunotherapy [3], may reduce this burden.

For policy makers, it is important to weigh the balance between the benefits and costs of such new interventions in an economic evaluation. Economic evaluations often express health benefits in terms of quality-adjusted life-years. This measure adjusts the life-years gained by a new intervention (vs. current practice) for health-related quality of life (HRQoL) using health state utility values (HSUVs). HSUVs are weights ranging from 0 to 1 , with 0 representing death and 1 representing full health. In some cases, values $<0$ are used to represent health states worse than death.

HSUVs can be elicited using a variety of methods. First, patients can be asked to directly value their own HRQoL. Valuation can be done using the choice-based time trade-off (TTO) or standard gamble (SG) methods or the non-choicebased visual analogue scale. In simple terms, choice-based methods determine what respondents would be willing to give up or risk to avoid living in that health state. Indirect elicitation methods are also available, such as asking patients to complete a generic (i.e. applicable across different diseases) multi-attribute instrument. Examples of such generic instruments are the EuroQoL 5-Dimensions (EQ-5D), the Short-Form Six Dimensions (SF-6D), and the Assessment of Quality of Life (AQoL). Based on their answers, each patient is assigned a health state that has been valued by members of the general public. These pre-determined valuation sets are called the tariff. Another indirect elicitation method is drafting vignettes that describe a patient's HRQoL and then asking individuals to value these vignettes. Finally, some studies have attempted to convert other HRQoL measures (such as the condition-specific European Organization for Research and Treatment of Cancer Quality of Life Questionnaire) to an existing generic multi-attribute instrument without using a valuation method. This practice is called mapping.

Most international guidelines, including those from the UK National Institute for Health and Care Excellence (NICE), prefer that the HRQoL of actual patients is valued by members of the general public (i.e. community based) using choice-based methods [4-6]. For reasons of comparability (e.g. across studies or diseases), the preferred instrument in most guidelines is the EQ-5D [5, 6].

Because of the broad variation in elicitation methods, HSUVs for lung cancer have been reported to vary drastically across the literature [7]. Using different HSUVs can lead to different policies being ranked as cost effective [8]. Therefore, it is important to systematically identify appropriate and high-quality HSUVs for economic evaluations [9].

Although earlier studies attempted to provide an overview of HSUVs for lung cancer, these only included metastatic non-small-cell lung cancer cases [10], were not systematic reviews [7], did not include an overview of study characteristics or a critical appraisal [7, 10], and did not provide a pooled set of methodologically high-quality HSUVs [7, 10]. Therefore, we aimed to provide a current systematic review of HSUVs for all types of lung cancer, including an overview of study characteristics and a critical appraisal, and a pooled set of community- and choice-based HSUVs for use in economic evaluations.

\section{Materials and Methods}

\subsection{Study Protocol}

The protocol for this study was prospectively registered in the PROSPERO database (reference number CRD42018081495) [11]. This study was undertaken in concordance with the PRISMA (Preferred Reporting Items for Systematic Reviews and Meta-Analyses) statement [12]; the Cochrane Handbook for Systematic Reviews [13]; the good practices report by the International Society for 
Pharmacoeconomics and Outcomes Research, Identification, Review, and Use of Health State Utilities in Cost-Effectiveness Models [9]; a similar technical support document developed for NICE [14]; and recent guidance published in PharmacoEconomics [15].

\subsection{Search Strategy}

A broad and systematic search was conducted in the Embase, Ovid MEDLINE, Web of Science, Cochrane CENTRAL, Google Scholar, and School of Health and Related Research Health Utility Database (ScHARRHUD) databases on 6 March 2017 and updated on 17 April 2019. In short, synonyms for lung cancer were combined with synonyms for health state utility values; quality of life; different analyses, methods, and instruments suitable for eliciting HSUVs; and different valuation techniques. Conference abstracts, letters, notes, commentaries, and editorials were excluded. The complete syntax is provided in the electronic supplementary material (ESM 1; Methods).

\subsection{Study Selection}

We used Endnote X9 software to remove duplicates [16]. The first and second authors screened titles and abstracts of all initial references according to a pre-specified algorithm, which was designed to broadly identify studies that may report lung cancer-specific HSUVs elicited using any technique (see the Methods in ESM 1). In short, references were selected when the title or abstract indicated that (1) study results were likely lung cancer specific and (2) HSUVs were measured, or HRQoL was measured using an instrument suitable to elicit HSUVs, or HRQoL scores from another instrument were mapped onto a utility scale, or HRQoL was measured and the use of a valuation method was mentioned, or the study was a cost-utility analysis, or the study was a quality-adjusted-survival study. References included by only one of both reviewers were discussed until reaching consensus. References added after the search update were only screened by the first author.

The full text of selected articles was subsequently screened by the first author according to a second pre-specified algorithm (see the Methods in ESM 1) and discussed with the second author. In short, studies were included for critical appraisal if the full text reported at least one original (i.e. not previously published) lung cancer-specific mean or median HSUV, including a measure of variance. Only studies written in English or Dutch language were considered. Conference abstracts were not considered because these often present only preliminary, incomplete, or non-peerreviewed data. Secondary literature (e.g. literature reviews and cost-utility analyses that sourced HSUVs from the literature) was excluded but checked for cross-references.
Articles selected for full-text screening were also checked for cross-references.

\subsection{Data Extraction and Critical Appraisal}

A digital data extraction form was developed in Microsoft Excel 2016, piloted on six studies, and subsequently refined. First, study characteristics were extracted for use in a critical appraisal. We developed a customised critical appraisal tool for assessing the relevance and validity of the selected studies, based on HSUV-relevant items from several established tools and good practices reports [9, 14, 17-19]. In concordance with most international guidelines, study relevance was deemed high if HRQoL was measured in actual patients, whereas a choice-based method was used by members of the general public to value HSUVs (i.e. elicitation was community- and choice-based) [6]. Studies that scored insufficiently on any of these relevance items were excluded from subsequent analyses. This approach prioritises consistency of the methodology across studies [9].

For the remaining studies, all study characteristics that may affect HSUVs were extracted and summarised. If a single study (or multiple studies using the same data) applied different tariffs to the same HRQoL data, only the analysis that applied the matching tariff was extracted (i.e. the tariff matching the country of participants from whom HRQoL was measured). Similarly, if a single study applied multiple instruments to the same patients, only the most commonly preferred instrument was extracted. In accordance with several international guidelines, including those of NICE, the EQ-5D was preferred, followed by other generic preferencebased instruments, and finally any remaining methods [5, 6]. Again, this approach prioritised consistency of methodology across studies. Data were extracted by the first author and subsequently discussed with the second author.

\subsection{Meta-Analysis and Statistical Methods}

All studies remaining after critical appraisal were included in subsequent analyses, if appropriate. Mean or median HSUVs and standard errors were extracted. If standard errors were not available, they were calculated using available information [13]. If median HSUVs were reported, standard deviations were estimated by dividing the interquartile range by 1.35 [13]. Then, the estimated standard deviation was used to calculate the standard error. For studies that reported HSUVs for a control group of the general population, we formally tested the disutility due to lung cancer using a $t$ test, assuming unequal variances. For mapping studies, we extracted the observed HSUV data, if available.

If necessary, we first pooled mean HSUVs across strata within studies using a fixed-effects model [20,21]. For studies measuring HSUVs at multiple time points in the 
same individuals, we only extracted and pooled the HSUV at the time point closest to baseline to avoid violating the assumption of independence of observations [22, 23].

As clinical and study characteristics were expected to vary across studies [7], HSUVs across the different studies were then pooled using a random-effects model [20, 24]. To account for possible differences in HSUVs by stage [7, 25], results were separately pooled for studies reporting HSUVs for all stages, for stages I-II, and for stages III-IV. Differences between the pooled HSUVs for stages I-II and stages III-IV were formally tested using a $t$ test, assuming unequal variances.

The study selection based on our critical appraisal accounts for several potential sources of heterogeneity, including the respondent type (i.e. only patients) [7], the elicitation method (i.e. only indirect), the valuation method (i.e. only community- and choice-based) [7, 25, 26], and the upper bound of the utility scale (i.e. only perfect health) [7]. To account for further sources of heterogeneity, a sensitivity analysis pooled HSUVs only across studies that explicitly used the three-level EQ-5D (EQ$5 \mathrm{D}-3 \mathrm{~L}$ ) instrument. A second sensitivity analysis included only studies that used the EQ-5D instrument (regardless of the version), while also applying the tariff matching the country of HRQoL respondents [9, 27, 28]. This second sensitivity analysis aimed to provide the methodologically most comparable HSUVs for each available country. We further conducted exploratory subgroup analyses by histology (non-small cell vs. small cell) [7], sex [27], age [27], treatment modality, treatment line, and progression status. Results of the second sensitivity analysis and the different subgroup analyses were not pooled because of the anticipated low numbers of studies within each group.

Meta-analysis was performed in $\mathrm{R}$ software version 3.6.1 [29] using the meta [30] and metafor [31] packages. We did not assess the risk of publication bias in a funnel plot, which is recommended in the PRISMA checklist for systematic reviews [12], because this is not meaningful for continuous outcomes in a single group.

\section{Results}

\subsection{Search Strategy and Study Selection}

After removing duplicates, our search included 5828 studies. We further identified 13 studies by cross-referencing. After screening the titles and abstracts of all identified studies, we assessed the full text of 458 studies. Of those, 407 studies were excluded for reasons outlined in Fig. 1, leaving 51 studies for inclusion in the critical appraisal.

\subsection{Critical Appraisal}

The relevance of 27 of the 51 studies was high (see Table 1 in ESM 1) [32-58]. Of these, one study separately analysed two datasets [36], which were treated as separate studies. The remaining 24 studies were excluded from subsequent analyses [59-82]. Among the excluded studies, four did not measure HRQoL in patients [72, 77, 81, 82], nine did not use valuation by members of the general public $[59,60,63$, $69,71,72,74,81,82], 11$ did not use a choice-based method for valuation $[59,63,65,67-71,74,76,81]$, and nine had missing data on one or more of these items $[61,62,64,66$, 73, 75, 78-80].

Among the included studies, the number of patients included for HSUV analysis ranged from 43 to 2396. Only two of 27 studies clearly stated that missing HRQoL data were imputed or that HRQoL response was complete [37, 47]. Six studies performed multiple HRQoL measurements in the same participants. Two of those studies, which used time-to-death categories, did not report loss to follow-up $[57,58]$. These two studies were analysed separately because the time since diagnosis could not be derived. The other four studies with repeated measures all reported loss to follow-up at each evaluated time point $[40,46,50,52]$.

\subsection{Study Characteristics}

Characteristics of the included studies are provided in Tables 2a-c (see ESM 1). One study included only stage I and/or II cases [47], and 13 studies included only stage III and/or IV cases [35-39, 44, 45, 48, 49, 51, 52, 57, 58]. However, two of these stage III-IV studies stratified HSUVs by time to death $[57,58]$. These studies were analysed in a separate subgroup analysis. Five of the 13 studies that included all stages stratified HSUVs by stage [33, 34, 40, $42,46]$. Thus, the main analysis included 13 studies with HSUVs for all stages [32-34, 40-43, 46, 50, 53-56], six studies with HSUVs for stages I-II [33, 34, 40, 42, 46, 47], and 17 analyses across 16 studies with HSUVs for stage III-IV [33-40, 42, 44-46, 48, 49, 51, 52].

Eight of the included studies reported mean time since diagnosis [32, 33, 36, 37, 42, 43, 50, 53], which ranged from 27 days to 2.59 years. Most included studies used the EQ-5D instrument: one study used the AQoL instrument [40] and two studies used the SF-6D instrument [43, 54]. Among EQ-5D studies, six did not specify the version used [32, 37, 45, 48, 49, 56], one used the new fivelevel EQ-5D (EQ-5D-5L) [55], and 14 used the EQ-5D-3L [33-36, 38, 39, 41, 42, 44, 46, 47, 50, 51, 53]. The 14 studies that explicitly used the EQ-5D-3L were separately pooled in a sensitivity analysis. All EQ-5D studies and the AQoL study used the TTO method for valuation, whereas the SF-6D studies used the SG method. Only three studies 


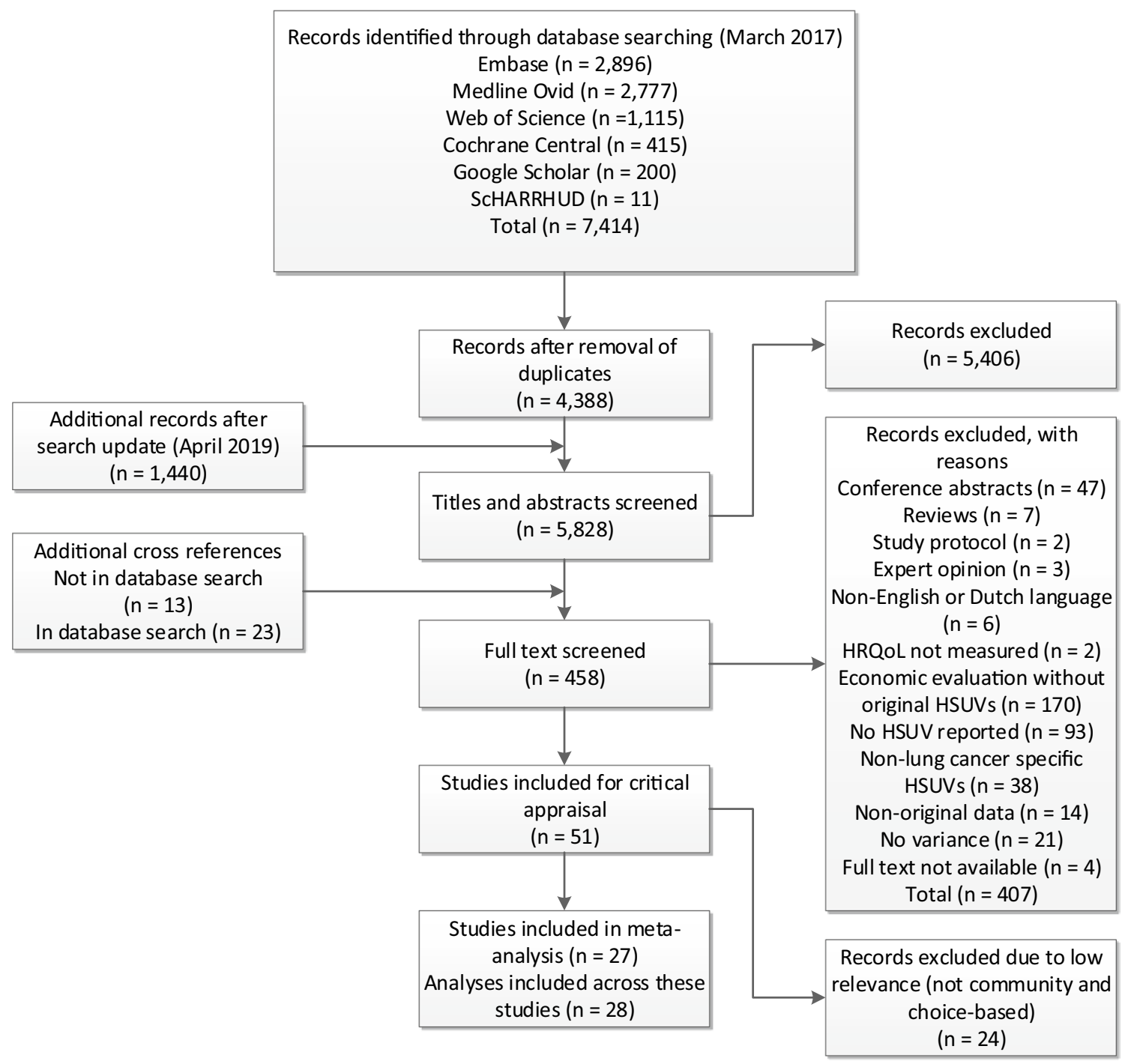

Fig. 1 Flowchart of selection of studies reporting community- and choice-based health state utility values for lung cancer. $H R Q O L$ health-related quality of life, HSUV health state utility value, ScHARRHUD School of Health and Related Research Health Utility Database

collected data through a personal interview [32, 46, 55]. Most of the studies reported mean HSUVs (one reported median HSUVs [40]).

Of 27 studies, 13 applied the tariff that matched the country of origin of the HRQoL respondents [36, 39-42, $44-47,49,50,53,55]$. One of these 13 studies did not use the EQ-5D instrument [40]. The remaining 12 studies, which comprised 13 analyses, were included in a second sensitivity analysis of the methodologically most comparable HSUVs for each country [36, 39, 41, 42, 44-47, 49, 50, 53, 55].

In total, 12 studies included only non-small-cell lung cancer [33-38, 41, 47, 49-52]. The remaining studies included all lung cancer cases regardless of histology. Of these studies, three provided histology-specific HSUVs [46, 48, 53]. However, one of these studies included only cases with stage IIIb-IV lung cancer [48]. For reasons of comparability across studies, only the remaining two studies were included in a subgroup analysis by histology $[46,53]$.

The percentage of male patients ranged between 37 and 93\%. Five studies provided HSUVs stratified by sex [33, 40, 46, 48, 53]. However, one of these studies only included stage IIIb-IV lung cancer cases [48]. Thus, the remaining four studies were included in a subgroup analysis of HSUVs by sex [33, 40, 46, 53].

The mean or median age of patients ranged between 51 and 70 years. Five studies stratified HSUVs by age [33, 40, $46,48,53]$. Two of those studies did not provide the number of patients in the different age groups [48, 53]. Of the remaining three studies, which included all stages of lung cancer, two used similar age categories. These two studies were included in a subgroup analysis of HSUVs by age [40, 46]. 
A total of 13 studies allowed the derivation of treatmentspecific HSUVs, either by inclusion criteria or by HSUV stratification [33-39, 44-47, 49, 53]. However, only seven of these studies allowed the derivation of HSUVs according to treatment modality (surgery, radiotherapy, chemotherapy, or a combination of those) [33, 37, 39, 44, 46, 47, 49]. Of these seven studies, two included all stages of lung cancer. Because the recommended treatment modality for lung cancer is mainly based on stage, a subgroup analysis of HSUVs by treatment modality was conducted using these two studies $[33,46]$. Only one study was identified that reported HSUVs by treatment line [38]. This study was included in a further subgroup analysis by treatment line.
We identified two studies reporting HSUVs by progression status $[38,49]$. Both studies included only patients with metastatic non-small-cell lung cancer. These studies were included in a subgroup analysis by progression status.

\subsection{Health State Utility Values}

Figure 2 provides an overview of HSUVs across all included studies. The pooled HSUV for all stages was 0.68 (95\% confidence interval [CI] 0.61-0.75) across 5100 individuals. HSUV s for all stages ranged from 0.51 (95\% CI 0.49-0.53) [50] to 0.81 (95\% CI 0.78-0.84) [43], indicating the presence of significant heterogeneity $(p<0.01)$. Most heterogeneity
Fig. 2 Pooled results of studies reporting community- and choice-based health state utility values for lung cancer by stage. The size of the symbol representing the effect size in each study is relative to the weight it had in random-effects meta-analysis. Not all studies included both stage I-II and stage III-IV cases. Not all studies that did include all stages stratified by stage. The total number of individuals contributing to the pooled value for all stages was 5100; the total number was 1510 for stages I-II and 4703 for stages III-IV. The difference between the pooled values for stages I-II and III-IV was statistically significant $(p=0.02)$. Arabic numerals between square brackets next to author names refer to the reference list. $C I$ confidence interval

$\begin{array}{lcl}\text { Source } & \mathbf{N} & \text { Mean utility }(95 \% \\ \text { Stage = AlI } & & \\ \text { Kimman 2015 [32] } & 624 & 0.61[0.60 ; 0.62] \\ \text { Grutters 2010 [33] } & 245 & 0.74[0.71 ; 0.77] \\ \text { Jang 2010 [34] } & 172 & 0.76[0.73 ; 0.79] \\ \text { Manser 2006 [40] } & 91 & 0.67[0.61 ; 0.73] \\ \text { Khan 2016 [41] } & 97 & 0.52[0.45 ; 0.58] \\ \text { Naik 2017 [42] } & 149 & 0.78[0.74 ; 0.82] \\ \text { Shih 2006 [43] } & 51 & 0.81[0.78 ; 0.84] \\ \text { Tramontano 2015 [46] } & 2396 & 0.78[0.77 ; 0.79] \\ \text { Maximiano 2018 [50] } & 495 & 0.51[0.49 ; 0.53] \\ \text { O'Kane 2019 [53] } & 519 & 0.75[0.74 ; 0.77] \\ \text { Rendas-Baum 2019 [54] } & 43 & 0.58[0.54 ; 0.62] \\ \text { Su 2019 [55] } & 104 & 0.75[0.70 ; 0.81] \\ \text { Sullivan 2011 [56] } & 114 & 0.56[0.48 ; 0.64] \\ \text { Total } & & 0.68[0.61 ; 0.75] \\ \text { Heterogeneity: } \chi_{12}^{2}=1082.29(P<.01), I^{2}=99 \% \\ & & \\ \text { Stage = I-II } & & \\ \text { Grutters 2010 [33] } & 144 & 0.76[0.72 ; 0.80] \\ \text { Jang 2010 [34] } & 50 & 0.80[0.74 ; 0.85] \\ \text { Manser 2006 [40] } & 44 & 0.62[0.51 ; 0.72] \\ \text { Naik 2017 [42] } & 89 & 0.78[0.74 ; 0.82] \\ \text { Tramontano 2015 [46] } & 982 & 0.80[0.79 ; 0.81] \\ \text { Bendixen 2019 [47] } & 201 & 0.88[0.86 ; 0.90] \\ \text { Total } & & 0.78[0.70 ; 0.86] \\ \text { Heterogeneity: } \chi_{5}^{2}=66.29(P<.01), I^{2}=92 \% \\ \text { Stage = III-IV } & & \\ \text { Grutters 2010 [33] } & 101 & 0.71[0.65 ; 0.76] \\ \text { Jang 2010 [34] } & 122 & 0.75[0.72 ; 0.78] \\ \text { Schuette 2012 [35] } & 231 & 0.66[0.63 ; 0.69] \\ \text { Khan 2014 (a) [36] } & 670 & 0.61[0.59 ; 0.63] \\ \text { Khan 2014 (b) [36] } & 130 & 0.75[0.71 ; 0.79] \\ \text { van den Hout 2006 [37] } & 297 & 0.57[0.53 ; 0.61] \\ \text { Chouaid 2013 [38] } & 255 & 0.66[0.62 ; 0.70] \\ \text { Matter-Walstra 2014 [39] } & 154 & 0.85[0.83 ; 0.87] \\ \text { Manser 2006 [40] } & 45 & 0.68[0.61 ; 0.74] \\ \text { Naik 2017 [42] } & 60 & 0.77[0.71 ; 0.83] \\ \text { Pickard 2007 [44] } & 50 & 0.74[0.70 ; 0.78] \\ \text { Thongprasert 2015 [45] } & 150 & 0.67[0.62 ; 0.72] \\ \text { Tramontano 2015 [46] } & 1277 & 0.77[0.76 ; 0.78] \\ \text { Erbaycu 2018 [48] } & 266 & 0.66[0.61 ; 0.70] \\ \text { Limwattananon 2018 [49] } & 135 & 0.62[0.58 ; 0.65] \\ \text { Mendoza 2018 [51] } & 664 & 0.51[0.48 ; 0.54] \\ \text { Meregaglia 2019 [52] } & 96 & 0.77[0.73 ; 0.80] \\ \text { Total } & & 0.69[0.65 ; 0.73] \\ \text { Heterogeneity: } \chi_{16}^{2}=682.41 & (P<.01), I^{2}=98 \% \\ & & \end{array}$

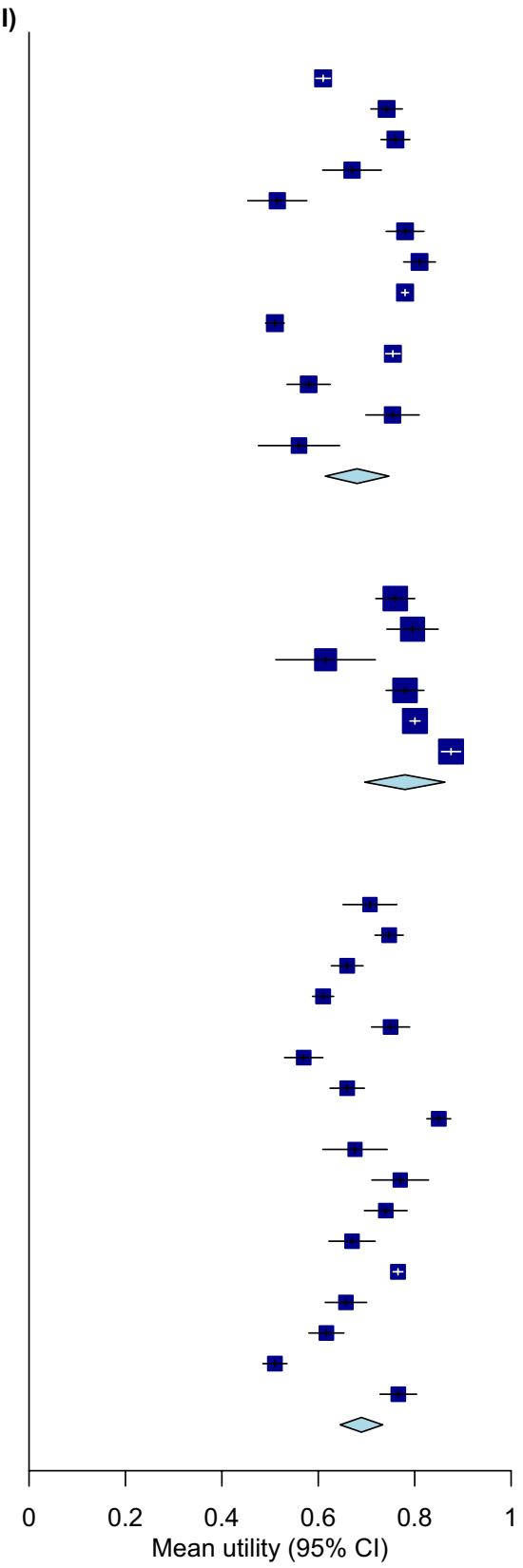


could not be attributed to sampling error $\left(I^{2}=99 \%\right)$. For stages I-II, the pooled HSUV was 0.78 (95\% CI 0.70-0.86) across 1510 individuals. There was significant heterogeneity across stage I-II studies ( $\left.p<0.01 ; I^{2}=92 \%\right)$, as results ranged from 0.62 (95\% CI 0.51-0.72) [40] to 0.88 (95\% CI $0.86-0.90)$ [47]. The pooled HSUV for stage III-IV was 0.69 (95\% CI 0.65-0.73) across 4703 individuals. The analysis of stage III-IV studies showed significant heterogeneity $\left(p<0.01 ; I^{2}=98 \%\right)$, with study results ranging from 0.51 (95\% CI 0.48-0.54) [51] to 0.85 (95\% CI 0.83-0.87) [39]. The difference between the pooled HSUV for stage I-II and stage III-IV was statistically significant $(p=0.02)$. In a sensitivity analysis, only studies that explicitly used the
EQ-5D-3L instrument were pooled (see Fig. 1 in the ESM 1). In this sensitivity analysis, the pooled HSUVs were similar to those in the main analysis.

Figures 3, 4 and 5 show the results of the sensitivity analysis of the 12 methodologically most comparable studies, which excluded non-EQ-5D studies and studies that did not apply the tariff matching the country of HRQoL respondents. All of these studies used TTO for valuation. For all stages, mean HSUVs ranged from 0.51 (95\% CI 0.49-0.53) in Spain [50] to 0.78 in the USA (95\% CI 0.77-0.79) [46] and Canada (95\% CI 0.74-0.82) [42] (see Fig. 3). For stages I-II, results ranged from 0.78 (95\% CI 0.74-0.82) for Canada [42] to 0.88 (95\% CI 0.86-0.90) for Denmark [47] (see Fig. 4). For

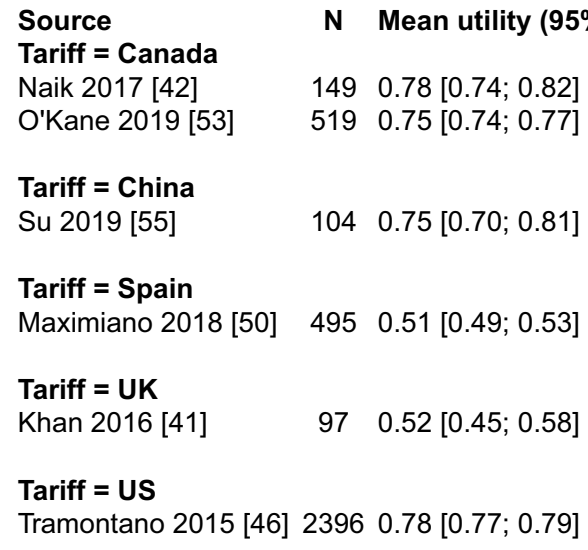

Fig. 3 Results of sensitivity analysis including only the methodologically most comparable studies reporting community- and choicebased health state utility values for all stages of lung cancer. Studies included in this sensitivity analysis used the EQ-5D instrument and applied the tariff matching the country of responding patients. Pooling results for this sensitivity analysis using a random-effects model was not possible because of the small number of studies within sub-

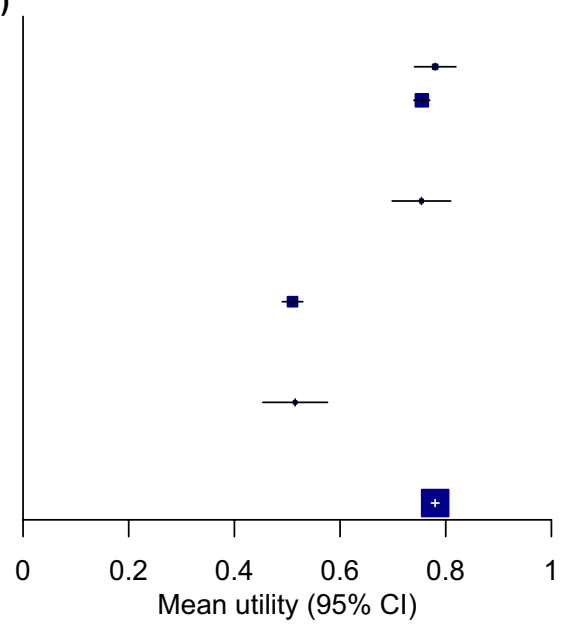

groups. The size of the symbol representing the effect size in each study is relative to the weight it would have in fixed-effects metaanalysis (i.e. relative to the inverse of its variance). Arabic numerals between square brackets next to the author names refer to the reference list. $C I$ confidence interval, $U K$ United Kingdom, US United States of America

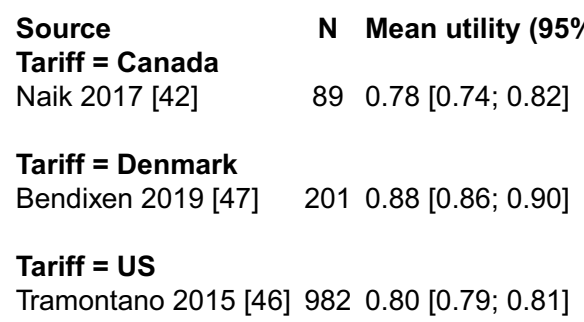

Fig. 4 Results of sensitivity analysis including only the methodologically most comparable studies reporting community- and choicebased health state utility values for stage I-II lung cancer. Studies included in this sensitivity analysis used the EQ-5D instrument and applied the tariff matching the country of responding patients. Pooling results for this sensitivity analysis using a random-effects model

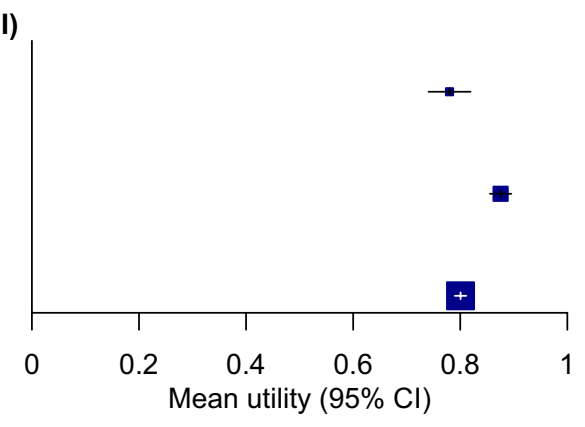

was not possible because of the small number of studies within subgroups. The size of the symbol representing the effect size in each study is relative to the weight it would have in fixed-effects metaanalysis (i.e. relative to the inverse of its variance). Arabic numerals between square brackets next to author names refer to the reference list. CI confidence interval, US United States of America 


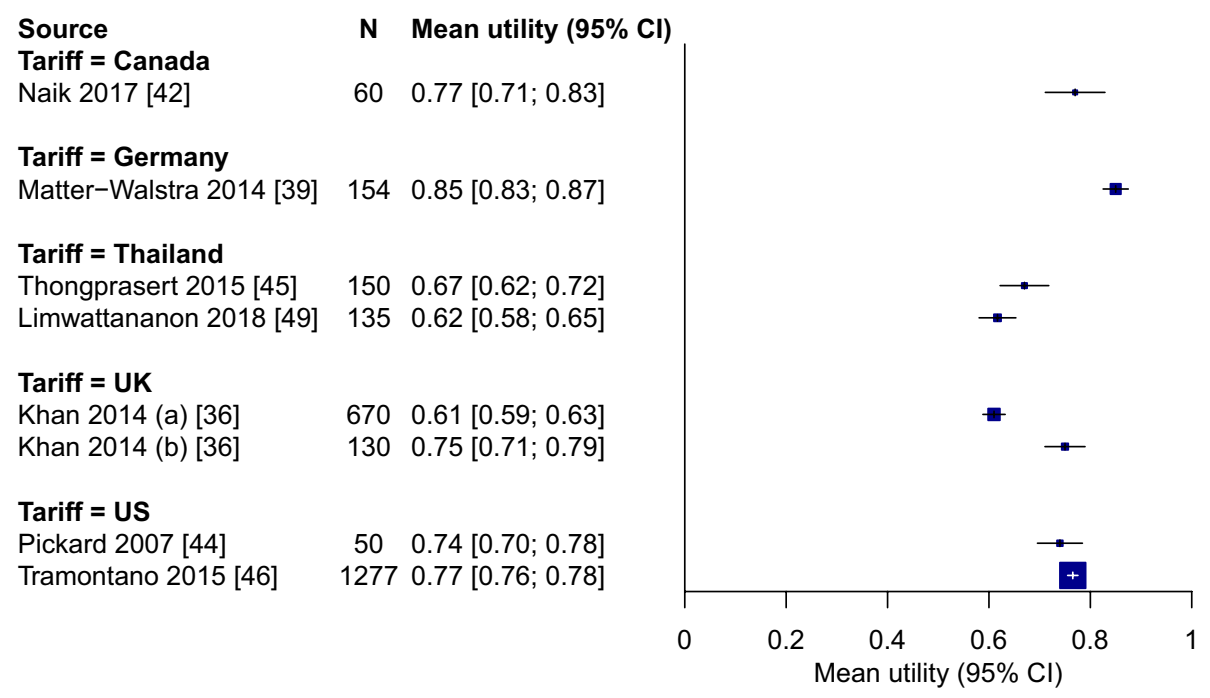

Fig. 5 Results of sensitivity analysis including only the methodologically most comparable studies reporting community- and choicebased health state utility values for stage III-IV lung cancer. Studies included in this sensitivity analysis used the EQ-5D instrument and applied the tariff matching the country of responding patients. Pooling results for this sensitivity analysis using a random-effects model was not possible because of the small number of studies within sub-

stage III-IV, the range was 0.61 (95\% CI 0.59-0.63) for a study in the UK [36] to 0.85 (95\% CI 0.83-0.87) in Germany [39] (see Fig. 5).

Among the two studies reporting HSUVs for patients with metastatic non-small-cell lung cancer by time to

groups. The size of the symbol representing the effect size in each study is relative to the weight it would have in fixed-effects metaanalysis (i.e. relative to the inverse of its variance). Arabic numerals between square brackets next to author names refer to the reference list. $C I$ confidence interval, $U K$ United Kingdom, $U S$ United States of America

death $[57,58]$, HSUVs decreased consistently throughout the last year of life (see Fig. 6). HSUVs ranged from 0.83 (95\% CI $0.82-0.85)$ at $\geq 360$ days from death to $0.56(95 \%$ CI 0.46-0.66) at $<30$ days from death. Both studies were

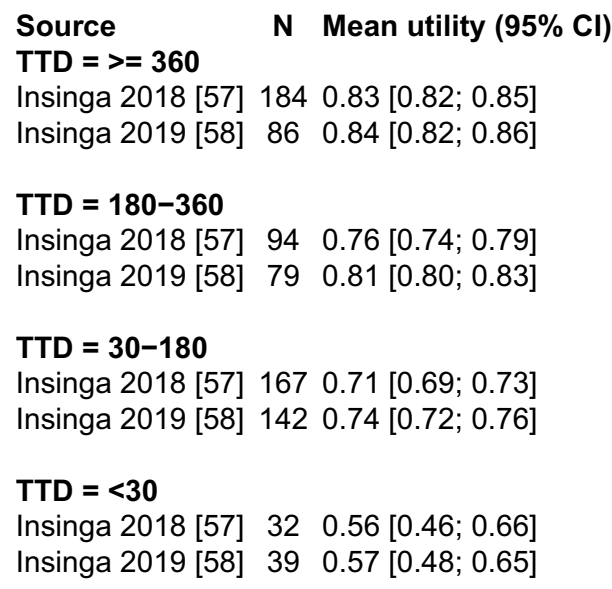

Fig. 6 Results of studies reporting community- and choice-based health state utility values for lung cancer by time to death. Patients could contribute to multiple time-to-death categories. Therefore, an overall pooled result could not be provided. The size of the symbol representing the effect size in each study is relative to the weight it

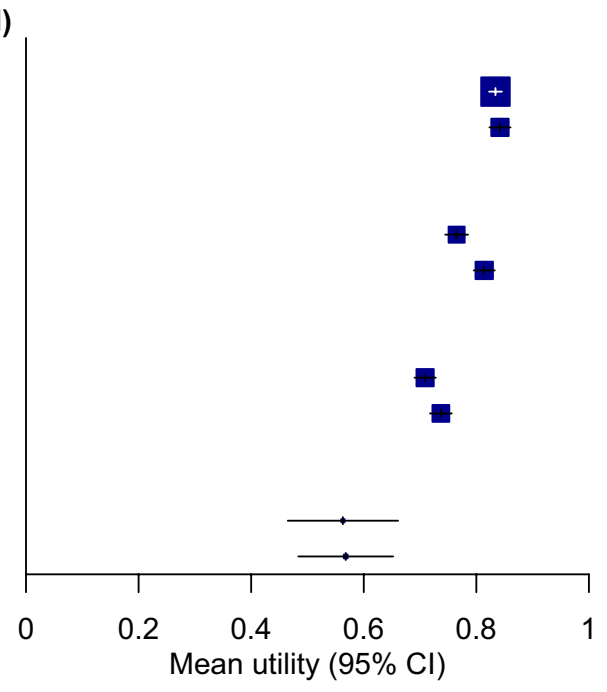

would have in fixed-effects meta-analysis (i.e. relative to the inverse of its variance). Arabic numerals between square brackets next to the author names refer to the reference list. $C I$ confidence interval, TTD time to death, expressed in days 
based in the USA and used the EQ-5D instrument with TTO valuation.

Results for the subgroup analysis by histology are shown in Fig. 2 in the ESM 1. The included studies both used the EQ-5D instrument with TTO valuation [46, 53]. The HSUV for non-small-cell lung cancer was similar in the US-based study by Tramontano et al. [46] and the Canadian study by O'Kane et al. [53]. In the US-based study, the HSUV for non-small-cell lung cancer $(0.78 ; 95 \%$ CI $0.77-0.79)$ was marginally higher than that for small-cell lung cancer $(0.76$; 95\% CI 0.74-0.78). In the smaller Canadian study, there was a more substantial difference in HSUV between non-smallcell lung cancer $(0.77$; $95 \%$ CI $0.76-0.79)$ and the HSUV for small-cell lung cancer $(0.63$; $95 \%$ CI $0.56-0.70)$.

As shown in Fig. 3 in the ESM 1, HSUVs for men did not differ substantially across the four studies included in the subgroup analysis by sex [33, 40, 46, 53]. HSUVs for men ranged from 0.72 (95\% CI 0.66-0.78) in the Australian study by Manser et al. [40], which applied the AQoL instrument with TTO valuation, to 0.78 (95\% CI 0.77-0.79) in the US-based study by Tramontano et al. [46], which applied the EQ-5D instrument with TTO valuation. In three of these studies, the HSUV for men was similar to that for women, which ranged from 0.73 (95\% CI 0.69-0.77) in the study by Grutters et al. [33], which applied the EQ-5D instrument to Dutch patients using the UK TTO valuation set, to 0.77 (95\% CI 0.76-0.78) in the US-based study by Tramontano et al. [46]. However, the Australian study by Manser et al. [40] reported substantially lower HSUV for women (0.52; 95\% CI 0.44-0.60).

Results for the subgroup analysis by age are shown in Fig. 4 in the ESM 1. In both age groups, HSUVs were higher in the US-based study by Tramontano et al. [46], which applied the EQ-5D instrument with TTO valuation, compared with the Australian study by Manser et al. [40], which applied the AQoL instrument with TTO valuation. In both of the included studies, the HSUV for patients aged $<65$ years was marginally lower than that for those aged $>65$ years. For example, in the US-based study, the HSUV for those aged $<65$ years was 0.76 (95\% CI $0.75-0.77$ ) compared with 0.80 (95\% CI $0.79-0.81$ ) for those aged $>65$ years [46].

Figure 5 in the ESM 1 shows the results for the subgroup analysis by treatment modality. In the Dutch study by Grutters et al. [33], which used the EQ-5D instrument with the UK TTO valuation set, HSUVs ranged from 0.62 (95\% CI $0.51-0.73$ ) among those receiving only radiotherapy to 0.86 (95\% CI 0.76-0.96) among those receiving surgery with radiotherapy. In the US-based study by Tramontano et al. [46], which also applied the EQ-5D instrument with TTO valuation, HSUVs ranged from 0.72 (95\% CI 0.67-0.77) among those receiving surgery and radiotherapy to 0.81 (95\% CI 0.80-0.82) among those receiving only surgery.
HSUV s by treatment line are shown in Fig. 6 in the ESM 1. Only one study was included in this subgroup analysis [38]. This study applied the EQ-5D instrument to a multinational selection of patients with metastatic non-small-cell lung cancer and applied the UK TTO tariff. The HSUV was 0.70 (95\% CI 0.66-0.74) for the first treatment line, 0.73 (95\% CI 0.67-0.78) for the second treatment line, and 0.57 (95\% CI 0.47-0.66) for the third and fourth treatment lines.

Figure 7 in the ESM 1 shows the results for the subgroup analysis of HSUVs by progression status [38, 49]. Both studies included patients with metastatic non-small-cell lung cancer and used the EQ-5D instrument. The multinational study by Chouaid et al. [38] applied the UK TTO tariff to all patients, whereas the Thai study by Limwattananon et al. [49] applied the matching Thai TTO tariff. In both studies, the HSUV for the 'progression free' health state was similar: 0.70 (95\% CI $0.66-0.74)$ in the study by Chouaid et al. [38] compared with 0.68 (95\% CI 0.62-0.74) in the study by Limwattananon et al. [49]. In the study by Chouaid et al. [38], the HSUV for the 'progressive' health state $(0.58 ; 95 \%$ CI 0.50-0.66) was substantially lower than the HSUV for the 'progression-free' health state $(0.70$; $95 \%$ CI $0.66-0.74)$. This was also the case for the study by Limwattananon et al. [49], although the 95\% CI for the 'progressive disease' health state was wide.

Finally, Table 3 in ESM 1 shows the results for the two studies that included a control group of members of the general population $[45,56]$. Both studies applied the EQ-5D instrument with TTO valuation. The difference in HSUV between lung cancer cases and controls (i.e. disutility) was 0.11 (95\% CI 0.05-0.17) in Thailand [45] and 0.27 (95\% CI $0.18-0.36$ ) in the study applying the UK tariff to HRQoL data from US patients [56]. In both studies, the disutility due to lung cancer was statistically significant $(p<0.01)$.

\section{Discussion}

To our knowledge, we are the first to provide a systematic review and meta-analysis of community- and choice-based HSUVs across all stages of lung cancer. Our pooled results show that the mean HSUV across the literature for stage I-II lung cancer $(0.78$; 95\% CI $0.70-0.86)$ is statistically significantly higher than the mean HSUV for stage III-IV lung cancer $(0.69 ; 95 \%$ CI $0.65-0.73)$. This makes sense, as stage I-II lung cancer can often be treated with curative intent, whereas metastatic disease (stage III-IV) often requires ongoing palliative treatment with chemotherapy and/or radiotherapy [83]. The pooled HSUV for all stages $(0.68 ; 95 \%$ CI $0.61-0.75)$ was close to that for stages III-IV, which is likely because lung cancer is most often diagnosed at stage IV [84]. 
While these pooled stage-specific HSUVs provide an overall mean HSUV across the literature, significant heterogeneity was present in all three stage groups, and this could not be explained by sampling error. In our sensitivity analysis that included only the methodologically most comparable studies, the most important study characteristics were the same (i.e. respondent type, stage of disease, elicitation method, instrument, valuation method, valuation population, and upper bound of the utility scale). Furthermore, these studies applied the tariff that matched the country of responding patients, which further reduced potential heterogeneity. Among these studies, stage-specific HSUVs strongly differed by country (and thus by tariff). Such studies were only identified for eight countries: Canada, China, Spain, the UK, the USA, Denmark, Germany, and Thailand. If stage-specific HSUVs provide sufficient granularity, authors of future economic evaluations of lung cancer interventions conducted in one of these eight countries may consider using HSUV s from the corresponding study identified in this sensitivity analysis. For example, a study seeking to investigate the cost effectiveness of lung cancer screening in the USA could use the stage-specific HSUVs from the study by Tramontano et al. [46]. However, for most countries, no such studies were identified. In addition, some authors may prioritise maximising the use of available data over selecting one methodologically optimal study. In both cases, our pooled analysis may provide the best available stage-specific HSUVs.

For some economic evaluations, stage-specific HSUVs may not provide sufficient granularity. For example, further stratification of HSUVs for metastatic lung cancer may be sought by treatment line or progression status. Subgroup analyses indicated that HSUVs for patients with metastatic non-small-cell lung cancer may indeed be lower among those with progressed disease and those undergoing a third or fourth line of treatment. Further exploratory subgroup analyses by histology, sex, age, and treatment modality did not provide unambiguous evidence for differences in HSUVs by these variables. For example, there were differences in HSUVs across treatment modalities within studies. However, the recommended and provided treatment modalities for lung cancer are mainly based on stage [85], which may partly explain these differences. In addition, results were inconsistent across studies. For example, receiving surgery with radiotherapy was associated with the lowest HSUV in one study but with the highest HSUV in another study. In general, few studies were available with the required level of granularity for each of the conducted subgroup analyses, reflecting the need for more high-quality research. The lack of clear evidence regarding the effect of histology, sex, age, and treatment modality on HSUVs provides additional support for our suggestion to use stage-specific (and, if available, country-specific) HSUVs, if possible. Still, if authors of economic evaluations require HSUVs for other health states, Tables $2 \mathrm{a}-\mathrm{c}$ in the ESM 1 provide a comprehensive breakdown of patient characteristics, methodological characteristics, and the stratification variables used in each of the included studies. These tables may be used to identify specific studies meeting the needs of such analyses.

We only identified two relevant studies that included a matched control group. In these studies, the disutility due to lung cancer was 0.11 (95\% CI 0.05-0.17) and 0.27 (95\% CI 0.18-0.36), respectively. For comparison, the minimally important difference in EQ-5D HSUVs (defined as the smallest change that is perceived by patients as beneficial or that would result in a change in treatment) has been estimated at 0.06 for the USA and 0.08 for the UK $[44,86]$. It is important that more future HSUV studies include an adequately matched control group of members of the general population. Otherwise, the disutility due to lung cancer could be overestimated, as members of the general public do not have perfect health $[27,56]$.

\subsection{Strengths and Limitations}

A major strength of our study is the inclusion of both smallcell and non-small-cell lung cancer, regardless of stage, whereas a previous review included only advanced nonsmall-cell lung cancer [10]. Our search strategy, which was constructed in collaboration with an information specialist, was also a major strength. We screened almost 6000 abstracts and over 450 full-text articles, identifying 51 peerreviewed studies reporting original HSUVs. Through this search strategy, we identified a broader range of relevant studies than did two earlier reviews. The first, which was not a systematic review, screened 147 abstracts, yielding 22 studies [7]. The second screened 1832 abstracts, yielding 34 inclusions, of which 16 appeared to be non-peer-reviewed conference abstracts (for some of these abstracts, we identified and included the full study). In addition, we included a thorough assessment of study characteristics, relevance, and validity, which allowed us to focus on comparable studies presenting the preferred community- and choice-based HSUVs. In contrast, the two previous reviews included studies regardless of quality and methodology, including expert opinions $[7,10]$.

The large number of identified studies and the assessment of study characteristics enabled us to select the methodologically most comparable community- and choice-based HSUV studies. Therefore, we could control for the most important factors that may affect HSUVs without relying on meta-regression, which can be prone to false-positive associations [87]. Nevertheless, heterogeneity remained present across the identified studies. These differences may be due to additional factors that we were not able to fully control for. 
First, the time of measurement relative to diagnosis or treatment may influence HSUVs [25, 28]. Unfortunately, we could not account for this possible effect in our main analysis. Many of the included studies in our meta-analysis did not report the mean time between diagnosis and HSUV measurement. Also, while 4 of 27 studies measured HSUVs at multiple time points in the same patients, we could only include a single time point in our main analysis to avoid violating the assumption of independent observations. For those studies, we included the observation closest to baseline to limit the variability of time points across studies. Despite these limitations, the subgroup analysis by time to death showed that HSUVs for metastatic non-small-cell lung cancer tended to decrease during the last year of life. In particular, HSUVs had decreased by approximately one-third by the last month of life. A possible way to adjust for this effect in economic evaluations is to proportionally adjust the chosen HSUV for metastatic disease during the last phase of life.

Second, it can be difficult to disentangle the effects of some variables, even when comparing methodologically similar studies. For example, one of the studies in our metaanalysis reported HSUVs for two UK-based trials [36]. Both trials measured HRQoL in patients with stage III-IV non-small-cell lung cancer using the EQ-5D instrument and used the UK TTO tariff for valuation. However, the mean HSUV was 0.61 (95\% CI 0.59-0.63) in the first trial and 0.75 (95\% CI 0.71-0.79) in the second trial. The mean age of participants was 77 years in the first trial and 62 years in the second trial. Also, participants in the first trial received erlotinib or placebo, whereas patients in the second trial received radiotherapy and chemotherapy. Therefore, both age and treatment may have driven these markedly different HSUVs. Unfortunately, reporting and stratification of HSUVs was inconsistent across studies in our meta-analysis, which limited our ability to disentangle such effects.

\section{Conclusions}

The presented evidence supports the use of stage-specific HSUVs for lung cancer. In addition, it supports the use of country-specific HSUVs. However, stage-specific HSUVs were not available for many countries. Therefore, our pooled HSUVs may provide the best available stage-specific HSUVs for most countries. For metastatic non-small-cell lung cancer, adjusting for the decreasing HSUVs in the last year of life may be considered. Based on a limited number of studies, further stratification of HSUVs for metastatic nonsmall-cell lung cancer by treatment line or progression status may also be considered. Little evidence exists to support the use of histology-, sex-, age-, or treatment modality-specific HSUVs. Still, if HSUVs for other health states are required, our comprehensive breakdown of study characteristics can help identify suitable studies.

Acknowledgements The authors thank Wichor Bramer, librarian and information specialist at the Erasmus Medical Center Rotterdam, for assistance in conducting the systematic literature search.

Author Contributions EFB is the guarantor of the content of the manuscript, including the data and analysis. EFB, KtH, and HJdK contributed to the conception and design of the work. EFB and $\mathrm{KtH}$ contributed to acquisition of data (literature search), EFB performed data analysis (meta-analysis), and $\mathrm{EFB}, \mathrm{KtH}$, and $\mathrm{HJdK}$ contributed to interpretation of the data. EFB drafted the manuscript, $\mathrm{KtH}$ and HJdK critically revised it for important intellectual content, and EFB, KtH, and $\mathrm{HJdK}$ approved the final version for publication. EFB, KtH, and HJdK agree to be accountable for all aspects of the work.

\section{Declarations}

Funding This work was supported by the National Cancer Institute at the National Institutes of Health (Grant number 1U01CA199284-01) as part of the Cancer Intervention and Surveillance Modelling Network (CISNET). The funders had no role in the design of the study; the collection, analysis, or interpretation of the data; the writing of the report; or the decision to submit the article for publication.

Conflicts of Interest $\mathrm{HJdK}, \mathrm{KtH}$, and EFB are members of the Cancer Intervention and Surveillance Modeling Network (CISNET) Lung working group (grant 1U01CA199284-01 from the National Cancer Institute). HJdK is the principal investigator of the NELSON trial (Dutch-Belgian Lung Cancer Screening Trial; Nederlands-Leuvens Longkanker Screenings onderzoek) and has received speaker fees for a lung symposium at the University of Zurich/MSD. KtH and EFB are researchers affiliated with the NELSON trial. HJdK and KtH received a grant from the University of Zurich to assess the cost effectiveness of computer tomography (CT) lung cancer screening in Switzerland. HJdK and $\mathrm{KtH}$ were involved in the Cancer Care Ontario Health Technology Assessment Study for CT Lung Cancer Screening in Canada. $\mathrm{KtH}$ is involved in the SELECT (Selection of Eligible People for Lung Cancer Screening using Electronic Primary Care DaTa) study. KtH was an invited speaker at the 17 th, $19^{\text {th }}$, and 20th World Conferences on Lung Cancer and the 5th Russian Society of Clinical Oncology conference, for which travel expenses were paid (in part).

Ethics Approval This systematic review and meta-analysis solely used data available from previously published manuscripts and does not involve human participants so did not require ethics approval.

Consent to Participate Not applicable.

Consent for Publication Not applicable.

Data Availability The data generated or analysed during the current study are available from the corresponding author on reasonable request.

Code availability Code used to conduct meta-analyses may be obtained from the corresponding author upon reasonable request.

Open Access This article is licensed under a Creative Commons Attribution-NonCommercial 4.0 International License, which permits any non-commercial use, sharing, adaptation, distribution and reproduction in any medium or format, as long as you give appropriate credit to the original author(s) and the source, provide a link to the Creative 
Commons licence, and indicate if changes were made. The images or other third party material in this article are included in the article's Creative Commons licence, unless indicated otherwise in a credit line to the material. If material is not included in the article's Creative Commons licence and your intended use is not permitted by statutory regulation or exceeds the permitted use, you will need to obtain permission directly from the copyright holder. To view a copy of this licence, visit http://creativecommons.org/licenses/by-nc/4.0/.

\section{References}

1. International Agency for Research on Cancer. Cancer Today (powered by GLOBOCAN 2018). https://publications.iarc.fr/ Databases/Iarc-Cancerbases/Cancer-Today-Powered-By-GLOBO CAN-2018-2018. Accessed 11 Nov 2019.

2. The National Lung Screening Trial Research Team. Reduced lungcancer mortality with low-dose computed tomographic screening. N Engl J Med. 2011;365(5):395-409.

3. Antonia SJ, Borghaei H, Ramalingam SS, Horn L, De Castro Carpeno J, Pluzanski A, et al. Four-year survival with nivolumab in patients with previously treated advanced non-small-cell lung cancer: a pooled analysis. Lancet Oncol. 2019;20(10):1395-408.

4. Neumann PJ, Goldie SJ, Weinstein MC. Preference-based measures in economic evaluation in health care. Annu Rev Public Health. 2000;21:587-611.

5. National Institute for Health and Care Excellence. Guide to the methods of technology appraisal 2013. nice.org.uk/process/pmg9. Published: 4 Apr 2013; Accessed 26 Nov 2019.

6. Rowen D, Azzabi Zouraq I, Chevrou-Severac H, van Hout B. International regulations and recommendations for utility data for health technology assessment. Pharmacoeconomics. 2017;35(Suppl 1):11-9.

7. Sturza J. A review and meta-analysis of utility values for lung cancer. Med Decis Mak. 2010;30(6):685-93.

8. de Kok I, Korfage IJ, van den Hout WB, Helmerhorst TJM, Habbema JDF, Essink-Bot ML, et al. Quality of life assumptions determine which cervical cancer screening strategies are costeffective. Int J Cancer. 2018;142(11):2383-93.

9. Brazier J, Ara R, Azzabi I, Busschbach J, Chevrou-Severac H, Crawford B, et al. Identification, review, and use of health state utilities in cost-effectiveness models: an ISPOR good practices for outcomes research task force report. Value Health. 2019;22(3):267-75.

10. Paracha N, Abdulla A, MacGilchrist KS. Systematic review of health state utility values in metastatic non-small cell lung cancer with a focus on previously treated patients. Health Qual Life Outcomes. 2018;16(1):179.

11. Blom EF, ten Haaf K, de Koning HJ. Protocol for Health state utility values for economic evaluations of lung cancer: a systematic review and meta-analysis (PROSPERO ID: CRD42018081495). https://www.crd.york.ac.uk/prospero/displ ay_record.php?ID=CRD42018081495. Published online 3 Jan 2018; Accessed 26 Nov 2019.

12. Moher D, Liberati A, Tetzlaff J, Altman DG, Group P. Preferred reporting items for systematic reviews and meta-analyses: the PRISMA statement. Ann Intern Med. 2009;151(4):264-9.

13. Higgins JPT, Thomas J, Chandler J, Cumpston M, Li T, Page MJ, Welch VA (editors). Cochrane Handbook for Systematic Reviews of Interventions version 6.0. https://www.training.cochrane.org/ handbook. Updated Jul 2019; Accessed 26 Nov 2019.
14. Papaioannou D, Brazier J, Paisley S. NICE Decision Support Unit Technical Support Document 9: the identification, review and synthesis of health state utility values from the literature. http:// nicedsu.org.uk/wp-content/uploads/2016/03/TSD9-HSUV-value s_FINAL.pdf. Published Oct 2010; Accessed 26 Nov 2019.

15. Petrou S, Kwon J, Madan J. A practical guide to conducting a systematic review and meta-analysis of health state utility values. Pharmacoeconomics. 2018;36(9):1043-61.

16. Endnote $X 9$ [computer program]. Clarivate analytics; 2019.

17. Calvert M, Blazeby J, Altman DG, Revicki DA, Moher D, Brundage MD, et al. Reporting of patient-reported outcomes in randomized trials: the CONSORT PRO extension. JAMA. 2013;309(8):814-22.

18. Wells GA, Shea B, O'Connell D, et al. The Newcastle-Ottawa Scale (NOS) for assessing the quality of nonrandomised studies in meta-analyses. http://www.ohri.ca/programs/clinical_epidemiolo gy/oxford.asp. Accessed 18 Oct 2019.

19. Higgins JP, Altman DG, Gotzsche PC, Juni P, Moher D, Oxman $\mathrm{AD}$, et al. The Cochrane Collaboration's tool for assessing risk of bias in randomised trials. BMJ. 2011;343:d5928.

20. Rao G, Lopez-Jimenez F, Boyd J, D’Amico F, Durant NH, Hlatky MA, et al. Methodological standards for meta-analyses and qualitative systematic reviews of cardiac prevention and treatment studies: a scientific statement from the American Heart Association. Circulation. 2017;136(10):e172-94.

21. Borenstein M, Hedges LV, Higgins JPT, Rothstein HR. Chapter 23: Independent subgroups within a study. In: Introduction to metaanalysis. Chichester: Wiley; 2009. https://doi.org/10.1002/97804 70743386 (ISBN: 9780470057247, 9780470743386).

22. Peters JL, Mengersen KL. Meta-analysis of repeated measures study designs. J Eval Clin Pract. 2008;14(5):941-50.

23. Borenstein M, Hedges LV, Higgins JPT, Rothstein HR. Chapter 24: multiple outcomes or time-points within a study. In: Introduction to meta-analysis. Chichester: Wiley; 2009. https ://doi.org/10.1002/9780470743386 (ISBN: 9780470057247, 9780470743386).

24. Borenstein M, Hedges LV, Higgins JPT, Rothstein HR. Chapter 13: fixed effects versus random effects models. In: Introduction to meta-analysis. Chichester: Wiley; 2009. https:// doi.org/10.1002/9780470743386 (ISBN: 9780470057247, 9780470743386)

25. Djalalov S, Rabeneck L, Tomlinson G, Bremner KE, Hilsden R, Hoch JS. A review and meta-analysis of colorectal cancer utilities. Med Decis Mak. 2014;34(6):809-18.

26. Paracha N, Thuresson PO, Moreno SG, MacGilchrist KS. Health state utility values in locally advanced and metastatic breast cancer by treatment line: a systematic review. Expert Rev Pharmacoecon Outcomes Res. 2016;16(5):549-59.

27. Fryback DG, Dunham NC, Palta M, Hanmer J, Buechner J, Cherepanov D, et al. US norms for six generic health-related quality-of-life indexes from the National Health Measurement study. Med Care. 2007;45(12):1162-70.

28. Wolowacz SE, Briggs A, Belozeroff V, Clarke P, Doward L, Goeree R, et al. Estimating health-state utility for economic models in clinical studies: an ISPOR good research practices task force report. Value Health. 2016;19(6):704-19.

29. Team RC. R: a language and environment for statistical computing [computer program]. Version 3.6.1. Vienna: R Foundation for Statistical Computing; 2019. p. 2019.

30. Schwarzer G. meta: an R package for meta-analysis. R News. 2007;7(3):40-5.

31. Viechtbauer W. Conducting meta-analyses in $\mathrm{R}$ with the metafor package. J Stat Softw. 2010;36(3):1-48

32. Kimman M, Jan S, Monaghan H, Woodward M. The relationship between economic characteristics and health-related quality of 
life in newly diagnosed cancer patients in Southeast Asia: results from an observational study. Qual Life Res. 2015;24(4):937-49.

33. Grutters JPC, Joore MA, Wiegman EM, Langendijk JA, De Ruysscher D, Hochstenbag M, et al. Health-related quality of life in patients surviving non-small cell lung cancer. Thorax. 2010;65(10):903-7.

34. Jang RW, Isogai PK, Mittmann N, Bradbury PA, Shepherd FA, Feld R, et al. Derivation of utility values from European Organization for Research and Treatment of Cancer Quality of LifeCore 30 questionnaire values in lung cancer. J Thorac Oncol. 2010;5(12):1953-7.

35. Schuette W, Tesch H, Buttner H, Krause T, Soldatenkova V, Stoffregen C. Second-line Treatment of Stage III/IV Non-Small-Cell Lung Cancer (NSCLC) with pemetrexed in routine clinical practice: evaluation of performance status and health-related quality of life. BMC Cancer. 2012;12:1-12.

36. Khan I, Morris $\mathrm{S}$. A non-linear beta-binomial regression model for mapping EORTC QLQ-C30 to the EQ-5D-3L in lung cancer patients: a comparison with existing approaches. Health Qual Life Outcomes. 2014;12:1-16.

37. van den Hout WB, Kramer GWPM, Noordijk EM, Leer JWH. Cost-utility analysis of short- versus long-course palliative radiotherapy in patients with non-small-cell lung cancer. J Natl Cancer Inst. 2006;98(24):1786-94.

38. Chouaid C, Agulnik J, Goker E, Herder GJM, Lester JF, Vansteenkiste $\mathrm{J}$, et al. Health-related quality of life and utility in patients with advanced non-small-cell lung cancer: a prospective crosssectional patient survey in a real-world setting. J Thorac Oncol. 2013;8(8):997-1003.

39. Matter-Walstra K, Klingbiel D, Szucs T, Pestalozzi BC, Schwenkglenks M. Using the EuroQol EQ-5D in Swiss cancer patients, which value set should be applied? Pharmacoeconomics. 2014;32(6):591-9.

40. Manser RL, Wright G, Byrnes G, Hart D, Conron M, Carter R, et al. Validity of the Assessment of Quality of Life (AQoL) utility instrument in patients with operable and inoperable lung cancer. Lung Cancer. 2006;53(2):217-29.

41. Khan I, Morris S, Pashayan N, Matata B, Bashir Z, Maguirre J. Comparing the mapping between EQ-5D-5L, EQ-5D-3L and the EORTC-QLQ-C30 in non-small cell lung cancer patients. Health Qual Life Outcomes. 2016;14:1-15.

42. Naik H, Howell D, Su S, Qiu X, Brown MC, Vennettilli A, et al. EQ-5D health utility scores: data from a comprehensive Canadian Cancer Centre. Patient. 2017;10(1):105-15.

43. Shih YCT, Wang XS, Cantor SB, Cleeland CS. The association between symptom burdens and utility in Chinese cancer patients. Qual Life Res. 2006;15(8):1427-38.

44. Pickard AS, Neary MP, Cella D. Estimation of minimally important differences in EQ-5D utility and VAS scores in cancer. Health Qual Life Outcomes. 2007;5:1-8.

45. Thongprasert S, Crawford B, Sakulbumrungsil R, Chaiyakunapruk N, Petcharapiruch S, Leartsakulpanitch J, et al. Willingness to pay for lung cancer treatment: patient versus general public values. Int J Technol Assess Health Care. 2015;31(4):264-70.

46. Tramontano AC, Schrag DL, Malin JK, Miller MC, Weeks JC, Swan JS, et al. Catalog and comparison of societal preferences (utilities) for lung cancer health states: results from the Cancer Care Outcomes Research and Surveillance (CanCORS) study. Med Decis Mak. 2015;35(3):371-87.

47. Bendixen M, Kronborg C, Jorgensen OD, Andersen C, Licht PB. Cost-utility analysis of minimally invasive surgery for lung cancer: a randomized controlled trial. Eur J Cardiothorac Surg. 2019;56(4):754-61.

48. Erbaycu AE, Goksel T, Eser E, Gursul KK, Basarik B, Oz A, et al. The assessment of the effect of changes in lung cancer follow-up period on the quality of life using EQ-5D questionnaire and follow data (AKAYAK-1 multicenter project). Int J Hematol Oncol (UHOD). 2018;28(1):1-10.

49. Limwattananon C, Limwattananon S, Waleekhachonloet O, Rattanachotphanit T. Cost-effectiveness analysis of policy options on first-line treatments for advanced, non-small cell lung cancer in Thailand. Lung Cancer. 2018;120:91-7.

50. Maximiano C, López I, Martõn C, Zugazabeitia L, MartõCiriquián JL, Núñez MA, et al. An exploratory, large-scale study of pain and quality of life outcomes in cancer patients with moderate or severe pain, and variables predicting improvement. PLoS ONE. 2018;13(4):e0193233.

51. Mendoza TR, Dueck AC, Shi Q, Ma H, Zhang J, Qian Y, et al. The contribution of pain in determining the health status of cancer patients with bone metastases: a secondary analysis of data from three Phase III registration trials. Eur J Pain. 2018;22(3):565-71.

52. Meregaglia M, Borsoi L, Cairns J, Tarricone R. Mapping healthrelated quality of life scores from FACT-G, FAACT, and FACIT-F onto preference-based EQ-5D-5L utilities in non-small cell lung cancer cachexia. Eur J Health Econ. 2019;20(2):181-93.

53. O'Kane GM, Su J, Tse BC, Tam V, Tse T, Lu L, et al. The impact of brain metastases and associated neurocognitive aspects on health utility scores in EGFR mutated and ALK rearranged NSCLC: a real world evidence analysis. Oncologist. 2019;24(7):e501-9.

54. Rendas-Baum R, D'Alessio D, Bjorner JB. Health-related quality of life predicted subsequent health care resource utilization in patients with active cancer. Qual Life Res. 2019;28(4):1085-95.

55. Su M, Hua X, Wang J, Yao N, Zhao D, Liu W, et al. Health-related quality of life among cancer survivors in rural China. Qual Life Res. 2019;28(3):695-702.

56. Sullivan PW, Slejko JF, Sculpher MJ, Ghushchyan V. Catalogue of EQ-5D scores for the United Kingdom. Med Decis Mak. 2011;31(6):800-4.

57. Insinga RP, Vanness DJ, Feliciano JL, Vandormael K, Traore S, Burke T. Cost-effectiveness of pembrolizumab in combination with chemotherapy in the 1 st line treatment of non-squamous NSCLC in the US. J Med Econ. 2018;21(12):1191-205.

58. Insinga RP, Vanness DJ, Feliciano JL, Vandormael K, Traore S, Ejzykowicz F, et al. Cost-effectiveness of pembrolizumab in combination with chemotherapy versus chemotherapy and pembrolizumab monotherapy in the first-line treatment of squamous non-small-cell lung cancer in the US. Curr Med Res Opin. 2019;35(7):1241-56.

59. Yabroff KR, McNeel TS, Waldron WR, Davis WW, Brown ML, Clauser S, et al. Health limitations and quality of life associated with cancer and other chronic diseases by phase of care. Med Care. 2007;45(7):629-37.

60. Lee LJ, Chung CW, Chang YY, Lee YC, Yang CH, Liou SH, et al. Comparison of the quality of life between patients with non-small-cell lung cancer and healthy controls. Qual Life Res. 2011;20(3):415-23.

61. Trippoli S, Vaiani M, Lucioni C, Messori A. Quality of life and utility in patients with non-small cell lung cancer. Pharmacoeconomics. 2001;19(8):855-63.

62. Iyer S, Taylor-Stokes G, Roughley A. Symptom burden and quality of life in advanced non-small cell lung cancer patients in France and Germany. Lung Cancer. 2013;81(2):288-93.

63. Chouaid C, Bassinet L, Fuhrman C, Monnet I, Housset B. Routine use of granulocyte colony-stimulating factor is not cost- effective and does not increase patient comfort in the treatment of smallcell lung cancer: an analysis using a Markov model. J Clin Oncol. 1998;16(8):2700-7.

64. Blackhall F, Kim DW, Besse B, Nokihara H, Han JY, Wilner KD, et al. Patient-reported outcomes and quality of life in PROFILE 1007: a randomized trial of crizotinib compared 
with chemotherapy in previously treated patients with ALKpositive advanced non-small-cell lung cancer. J Thorac Oncol. 2014;9(11):1625-33.

65. Rauma V, Sintonen H, Räsänen JV, Salo JA, Ilonen IK. Long-term lung cancer survivors have permanently decreased quality of life after surgery. Clin Lung Cancer. 2015;16(1):40-5.

66. Geerse OP, Hoekstra-Weebers JEHM, Stokroos MH, Burgerhof JGM, Groen HJM, Kerstjens HAM, et al. Structural distress screening and supportive care for patients with lung cancer on systemic therapy: a randomised controlled trial. Eur J Cancer. 2017;72:37-45.

67. Lamers LM, Uyl-de Groot CA, Buijt I. The use of disease-specific outcome measures in cost-utility analysis: the development of Dutch societal preference weights for the FACT-L scale. Pharmacoeconomics. 2007;25(7):591-603.

68. Verduyn SC, Biesma B, Schramel FMNH, van der Scheer FW, Langenfeld MK, de Peuter MA, et al. Estimating quality adjusted progression free survival of first-line treatments for EGFR mutation positive non small cell lung cancer patients in the Netherlands. Health Qual Life Outcomes. 2012;10:1-7.

69. Burfeind WR Jr, Jaik NP, Villamizar N, Toloza EM, Harpole DH Jr, D'Amico TA. A cost-minimisation analysis of lobectomy: thoracoscopic versus posterolateral thoracotomy. Eur J Cardiothorac Surg. 2010;37(4):827-32.

70. Huang M, Lou Y, Pellissier J, Burke T, Liu FX, Xu R, et al. Costeffectiveness of pembrolizumab versus docetaxel for the treatment of previously treated PD-L1 positive advanced NSCLC patients in the United States. J Med Econ. 2017;20(2):140-50.

71. Papatheofanis FJ. Utility evaluations for Markov states of lung cancer for PET-based disease management. Q J Nucl Med. 2000;44(2):186-90.

72. Kennedy W, Reinharz D, Tessier G, Contandriopoulos AP, Trabut I, Champagne F, et al. Cost utility of chemotherapy and best supportive care in non-small cell lung cancer. Pharmacoeconomics. 1995;8(4):316-23.

73. Ilonen IK, Räsänen JV, Sihvo EI, Knuuttila A, Sovijärvi ARA, Sintonen $\mathrm{H}$, et al. Pneumonectomy: post-operative quality of life and lung function. Lung Cancer. 2007;58(3):397-402.

74. Ko CY, Maggard M, Livingston EH. Evaluating health utility in patients with melanoma, breast cancer, colon cancer, and lung cancer: a nationwide, population-based assessment. J Surg Res. 2003;114(1):1-5.

75. Galetta D, Cinieri S, Pisconti S, Gebbia V, Morabito A, Borsellino N, et al. Cisplatin/pemetrexed followed by maintenance pemetrexed versus carboplatin/paclitaxel/bevacizumab followed by maintenance bevacizumab in advanced nonsquamous lung cancer: The GOIM (Gruppo Oncologico Italia Meridionale) ERACLE phase III randomized trial. Clin Lung Cancer. 2015;16(4):262-73.
76. Huang M, Lou Y, Pellissier J, Burke T, Liu FX, Xu R, et al. Cost effectiveness of pembrolizumab vs. standard-of-care chemotherapy as first-line treatment for metastatic NSCLC that expresses high levels of PD-L1 in the United States. Pharmacoeconomics. 2017;35(8):831-44.

77. Kim EJ, Ock M, Kim KP, Jung NH, Lee HJ, Kim SH, et al. Disease severity-based evaluation of utility weights for lung cancerrelated health states in Korea. BMC Cancer. 2018;18(1):1-8.

78. Reck M, Brahmer J, Bennett B, Taylor F, Penrod JR, DeRosa M, et al. Evaluation of health-related quality of life and symptoms in patients with advanced non-squamous non-small cell lung cancer treated with nivolumab or docetaxel in CheckMate 057. Eur J Cancer. 2018;102:23-30.

79. Reck M, Taylor F, Penrod JR, DeRosa M, Morrissey L, Dastani $\mathrm{H}$, et al. Impact of nivolumab versus docetaxel on health-related quality of life and symptoms in patients with advanced squamous non-small cell lung cancer: results from the CheckMate 017 study. J Thorac Oncol. 2018;13(2):194-204.

80. Wood R, Taylor-Stokes G, Smith F, Chaib C. The humanistic burden of advanced non-small cell lung cancer (NSCLC) in Europe: a real-world survey linking patient clinical factors to patient and caregiver burden. Qual Life Res. 2019;28(7):1849-61.

81. Goodwin PJ, Feld R, Evans WK, Pater J. Cost-effectiveness of cancer chemotherapy: an economic evaluation of a randomized trial in small-cell lung cancer. J Clin Oncol. 1988;6(10):1537-47.

82. Cykert S, Kissling G, Hansen CJ. Patient preferences regarding possible outcomes of lung resection: what outcomes should preoperative evaluations target? Chest. 2000;117(6):1551-9.

83. National Comprehensive Cancer Network. Clinical Practice Guidelines in Oncology: Non-Small Cell Lung Cancer Version 5.2017. https://www.nccn.org/professionals/physician_gls/pdf/ nscl.pdf. Published 16 Mar 2017; Accessed 20 Apr 2017.

84. Chen VW, Ruiz BA, Hsieh M-C, Wu X-C, Ries LAG, Lewis DR. Analysis of stage and clinical/prognostic factors for lung cancer from SEER registries: AJCC staging and collaborative stage data collection system. Cancer. 2014;120(S23):3781-92.

85. Blom EF, ten Haaf K, Arenberg DA, de Koning HJ. Disparities in receiving guideline-concordant treatment for lung cancer in the United States. Ann Am Thorac Soc. 2020;17(2):186-94.

86. Walters SJ, Brazier JE. Comparison of the minimally important difference for two health state utility measures: EQ-5D and SF-6D. Qual Life Res. 2005;14(6):1523-32.

87. Peasgood T, Brazier J. Is meta-analysis for utility values appropriate given the potential impact different elicitation methods have on values? Pharmacoeconomics. 2015;33(11):1101-5. 